\title{
The Association Between HbA1c and 1-Year Diabetes- Related Medical Costs: A Retrospective Claims Database Analysis
}

\author{
Kristina S. Boye · Maureen J. Lage (D) · Vivian T. Thieu
}

Received: November 17, 2021 / Accepted: January 25, 2022 / Published online: February 7, 2022

(c) The Author(s) 2022

\section{ABSTRACT}

Introduction: The American Diabetes Association (ADA) has identified a target hemoglobin A1c $(\mathrm{HbA} 1 \mathrm{c})<7 \%$ as appropriate for most adults with type 2 diabetes (T2D). This research examines US diabetes-related healthcare costs for adults with T2D for individuals with glycemic control (HbA1c $<7 \%)$ compared to poor glycemic control (HbA1c $\geq 7 \%$ ).

Methods: The Optum Clinformatics ${ }^{\circledR}$ Data Mart database from 2016 to 2020 was used to identify a cohort of adults with T2D who had a recorded $\mathrm{HbA1c}$ test (with first such date identified as the index date) and continuous insurance from 1 year prior through 1 year post index date. Patients with glycemic control were propensity matched to patients with poor glycemic control. Generalized linear models and

Supplementary Information The online version contains supplementary material available at https:// doi.org/10.1007/s13300-022-01212-4.

K. S. Boye - V. T. Thieu

Eli Lilly and Company, 893 Delaware Street, Indianapolis, IN 46225, USAK. S. Boye e-mail: boye_kristina_secnik@lilly.com V. T. Thieu e-mail: thieu_vivian_thuyanh@lilly.com

M. J. Lage $(\square)$

HealthMetrics Outcomes Research, 17 Benton's

Knoll, Guilford, CT 06437, USA

e-mail: lagemj@hlthmetrics.com two-part models examined diabetes-related outpatient, drug, acute care, and total costs over the 1-year post-period.

Results: There were 34,538 propensity matched individuals included in the study. Results indicate that glycemic control (HbA1c $<7 \%$ ), compared to poor glycemic control (HbA1c $\geq 7 \%$ ), was associated with statistically significantly lower annual diabetes-related acute $(\$ 5671 \pm \$ 4216$ vs $\$ 6138 \pm \$ 4211)$, outpatient $(\$ 6051 \pm \$ 4216$ vs $\$ 7259 \pm \$ 7771)$, drug $(\$ 3739 \pm \$ 4581$ vs $\$ 4288 \pm \$ 4788)$, and total costs care $(\$ 13,704 \pm \$ 10,635 \quad$ vs $\$ 16,460 \pm \$ 10,885)$ (all $P<0.0001)$. Sensitivity analyses also examined results based upon alternative $\mathrm{HbA1c}$ thresholds which were chosen on the basis of expert guidelines and prior clinical trial thresholds $(<6 \%, \leq 6.5 \%,<8 \%$, and $\leq 9 \%$ ). In all cases, being below threshold was associated with statistically significantly lower diabetes-related total costs and component costs. Results also illustrate that, in general, higher HbA1c thresholds are associated with higher diabetes-related costs.

Conclusion: Glycemic control was found to be associated with significantly lower annual diabetes-related component and total costs. Results suggest economic benefits associated with having HbA1c at or below target. 
Keywords: Costs; Economics; HbA1c; Glycemic control; Propensity score matching; Type 2 diabetes

\section{Key Summary Points}

Why carry out this study?

Type 2 diabetes (T2D) is a large and increasing economic burden in the USA.

Many adults with T2D have been found to have less than optimal glycemic control.

This study examines the costs for suboptimal glycemic control (HbA1c $\geq 7 \%$ ).

What was learned from the study?

HbA1c below target was associated with significantly lower diabetes-related costs.

Results suggest significant economic benefits associated with lower HbA1c.

\section{INTRODUCTION}

An estimated $13.0 \%$ of all adults in the USA had diabetes in 2018 [1], and this figure is projected to increase to $17.9 \%$ by 2060 [2]. Commensurate with this high prevalence, diabetes is associated with substantial economic costs. For example, the total economic burden of diabetes in the USA was estimated at $\$ 327$ billion in 2017 [3]. This figure consisted of $\$ 237$ billion in direct medical costs and $\$ 90$ billion in reduced productivity [3]. Given that type 2 diabetes (T2D) accounts for approximately $90-95 \%$ of all cases of diagnosed diabetes [4], the majority of the costs associated with diabetes can be ascribed to T2D.

For individuals with T2D, the American Diabetes Association (ADA) recommends a target hemoglobin A1c (HbA1c) of $<7 \%$ for most nonpregnant adults [5]. This guideline is consistent with clinical trial results, which have illustrated the health benefits associated with glycemic control. For example, the Action in
Diabetes and Vascular Disease: Preterax and Diamicron MR Controlled Evaluation (ADVANCE) trial found that the cohort in the intensive glucose control arm (HbA1c target $\leq 6.5 \%$ ) had significantly fewer microvascular events $(14 \%$ relative risk reduction; $P=0.01)$ compared to the cohort in the standard glucose control arm [6]. Similarly, the Kumamoto Study found delayed onset and progression of microvascular complications associated with intensive glycemic control, which was defined as HbA1c $<6.5 \%$ [7]. The UK Prospective Diabetes Study (UKPDS) found that intensive glycemic control (mean $\mathrm{HbA} 1 \mathrm{c}=$ $7.0 \%)$, compared to conventional treatment (mean $\mathrm{HbA1c}=7.9 \%$ ), was associated with a $25 \%$ reduction in the risk of microvascular complications [8].

Despite the established clinical benefits of glycemic control, many patients fail to achieve the ADA's standard target of HbA1c $<7 \%$ [9]. Less is known about the economic consequences associated with different HbA1c target levels. The present research used a retrospective database to examine the hypothesis that glycemic control is associated with lower diabetesrelated costs and to provide timely estimates of the costs savings associated with glycemic control.

\section{METHODS}

The analyses were conducted using patient health information from the USA-based Optum ${ }^{\circledR}$ Clinformatics ${ }^{\circledR}$ Data Mart. The data is derived from a database of administrative health claims for geographically diverse members of large commercial and Medicare Advantage health plans which includes approximately 17-19 million annual covered lives. The linked data are fully de-identified and Health Insurance Portability and Accountability Act (HIPAA) compliant. For this study, the data set supplied longitudinal information on patient demographics, coverage eligibility, inpatient and outpatient services, outpatient prescription fills, payments, and laboratory test results. Data for this study covered the period from January 1 , 2016 through December 31, 2020 and 
permission to access the data was obtained from Optum $^{\circledR}$. Given the use of retrospective and deidentified data, ethics committee approval was not required.

Patients were required to have at least one recorded HbA1c result at any time from January 1, 2017 through December 31, 2019 (the identification window). For each patient, the date of the first such $\mathrm{HbA} 1 \mathrm{c}$ result was identified as the index date. Patients were also required to have had T2D during the 12 months prior to the index date (the pre-period) based upon receipt of two or more diagnoses of T2D and not more than one diagnosis of type 1 diabetes. Patients were excluded from the analyses if they were younger than age 18 years on the index date or were diagnosed with gestational diabetes or pregnancy at any time from the start of the preperiod through 1 year after the index date (the post-period). In order to ensure complete records of diagnoses, costs, and resource utilization, all patients were required to be continually insured from the start of the pre-period through the end of the post-period. Finally, patients who had more than 52 recorded HbA1c results during the post-period were excluded, since an issue with the source code resulted in the recording of an extensive number of HbA1c tests for a small subset of patients.

Consistent with ADA guidelines, which suggest that a target of HbA1c $<7 \%$ is appropriate for many nonpregnant adults with T2D [5], glycemic control was defined as HbA1c $<7 \%$, and patients were grouped on the basis of whether or not they met that HbA1c target on the index date. Propensity score matching (PSM) was used to match the group with HbA1c $<7 \%$ to the cohort with index HbA1c $\geq 7 \%$, utilizing a greedy nearest neighbor match without replacement and a specified caliper distance of 0.2 [10]. Covariates included in the PSM model were patient age, sex, race, region of residence, and insurance type. The final sample after PSM consisted of 34,538 patients. Figure 1 illustrates how each of the study inclusion and exclusion criteria affected sample size.

The primary outcome of interest was diabetes-related total medical costs. These costs, reported in 2020 US dollars, were defined as the total amount paid for all inpatient and outpatient services that had an accompanying diagnosis of diabetes and any outpatient prescription drugs filled for glucose-lowering agent (GLA) or diabetes supplies. In addition, costs were subcategorized into outpatient costs, acute care (inpatient and emergency room) costs, and drug costs. All cost measures were expressed as average per-patient annual costs in 2020 dollars, as adjusted by the medical component of the Consumer Price Index. [11].

Unadjusted descriptive statistics were summarized for the cohort overall as well as across index HbA1c thresholds $(<7 \%$ or $\geq 7 \%)$ post matching. Differences in continuous variables across groups were examined using $t$ statistics, while differences in categorical variables were examined using chi-square statistics. The relationships between index HbA1c and diabetesrelated healthcare costs were examined using multivariable analyses. Specifically, given the skewed nature of cost data, generalized linear models (GLM) with gamma distribution and log link [12] were used to examine diabetes-related total costs, outpatient costs, and drug costs, while diabetes-related acute care costs were examined using a two-part model. In this twopart model, the first step examined the probability of having an acute care visit and the second step examined acute care costs [13]. In the multivariable models, costs were estimated using the method of recycled predictions, with standard errors calculated from 1000 bootstrap iterations [14].

The multivariable analyses of diabetes-related costs controlled for patient demographics and pre-period statistics, including general health, comorbidities, resource utilization, and medication use. Patient demographic information included age, sex, race, region of residence, and insurance coverage. Patient general health and comorbidities were measured using the Diabetes Complications Severity Index (DCSI) and the adjusted Charlson Comorbidity Index (CCI). The DCSI is scored on a scale of $0-13$, with higher scores assigned to patients with a larger number of the following diagnoses: retinopathy, neuropathy, nephropathy, cerebrovascular disease, cardiovascular disease, peripheral vascular disease, and metabolic 


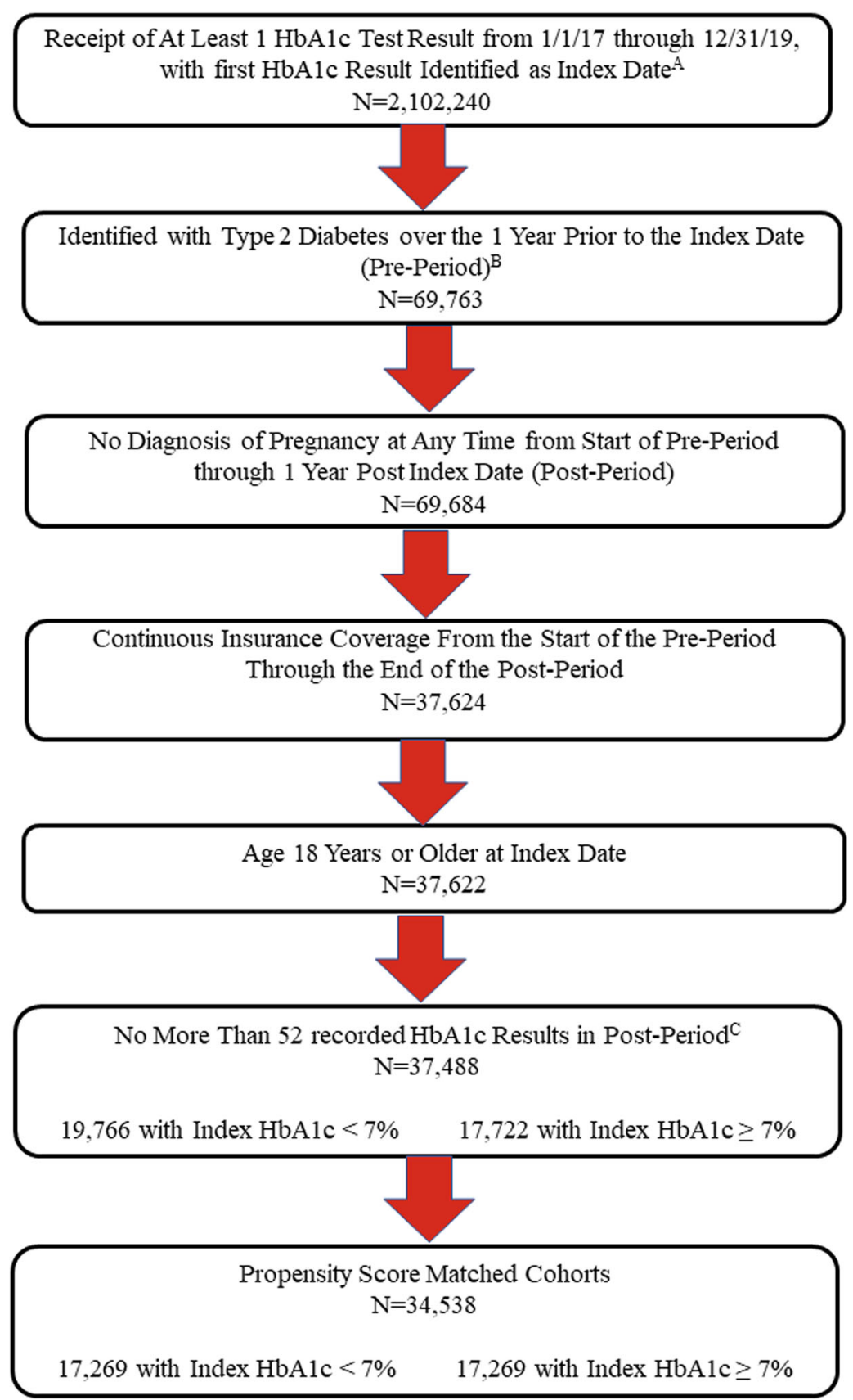

\begin{abstract}
A - Identification window time frame of $1 / 1 / 17$ through $12 / 31 / 19$ determined by the duration of the data $(1 / 1 / 16-12 / 31 / 20)$ and requirements of 1 -year pre and post-periods. B - Identification of type 2 diabetes (T2D) based upon receipt of 2 or more diagnoses of T2D and no more than 1 diagnosis of type 1 diabetes.

$\mathrm{C}$ - Requirement of no more than 52 recorded $\mathrm{HbAlc}$ results in the post-period due to a source coding error which resulted in an excessive number of $\mathrm{HbAl} \mathrm{c}$ recorded results for a small subset of patients.
\end{abstract}

Fig. 1 Study inclusion and exclusion criteria and sample size 
disease [15]. Meanwhile, the CCI creates a composite morbidity score that reflects mortality risk based upon the presence of any of 19 comorbidities, each scored on a scale of 1-6 [16]. In this study, the comorbidities of myocardial infarction, peripheral vascular disease, and diabetes with or without complications were omitted from the calculation of the adjusted CCI. These conditions were omitted either because they applied to all individuals (e.g., diabetes) or because they were included in the DCSI. In addition, the comorbidities of anxiety and depression, which are not included in either the CCI or DCSI, were included as covariates. Resource utilization was measured by indicator variables capturing whether the individual visited a cardiologist, endocrinologist, nephrologist, or ophthalmologist in the pre-period, as well as the number of pre-period visits to a family practitioner or internist. Preperiod medication use was measured by the number of classes of prescriptions filled for insulin, non-insulin GLAs, and non-GLAs.

All analyses were conducted using SAS, version 9.4 (Cary, NC), and a $P$ value $<0.05$ was considered, a priori, to be statistically significant.

\section{RESULTS}

Table 1 provides descriptive statistics for the cohort after PSM. Results indicate that the average patient was 72.7 years old (SD 10.3 years) and that the cohort consisted of more women $(53.1 \%)$ than men $(46.9 \%)$. The majority of patients were white $(53.7 \%)$ and resided in the South $(50.3 \%)$. After matching, significant differences remained between the two cohorts, with patients with HbA1c below threshold at index date found to be significantly older, more likely to be female, and more likely to be insured via a health maintenance organization. However, the absolute value of the standardized difference for all covariates, except for age, included in PSM was $<0.1$ after matching, the absolute value of the standardized difference of the mean propensity score was 0.07 , and the ratio of variances between the individuals with $\mathrm{HbA1c}$ below target to those with index HbA1c at or above target was 1.04 (See Supplementary Material). All of these results suggest balance between the two cohorts $[17,18]$.

Figure 2 illustrates the results of the multivariable analyses that examined differences in annual diabetes-related costs associated with index $\mathrm{HbA} 1 \mathrm{c}<7 \%$ compared to $\geq 7 \%$. Individuals who achieved the HbA1c target of $<7 \%$ were found to have significantly lower diabetesrelated total costs, drug costs, outpatient costs, and acute care costs. Annual diabetes-related total costs were $16.7 \%$ lower for those with HbA1c $<7 \%$ compared to patients with HbA1c $\geq 7 \% \quad(\$ 13,704 \pm \$ 10,635 \quad$ vs $\$ 16,460 \pm \$ 10,885 ; P<0.0001)$. In addition to having significantly lower total diabetes-related costs, lower HbA1c was also associated with statistically significantly lower diabetes-related outpatient costs $(\$ 6051 \pm \$ 6879 \quad$ vs $\$ 7259 \pm \$ 7771 ; P<0.0001)$, acute care costs $(\$ 5671 \pm \$ 4216 \quad$ vs $\quad \$ 6138 \pm \$ 4211$; $P<0.0001)$, and drug costs $(\$ 3739 \pm \$ 4581$ vs $\$ 4288 \pm \$ 4787 ; P<0.0001)$.

As a test of the sensitivity of the results, all analyses were examined using alternative HbA1c thresholds. In these analyses, targets of $<6 \%, \leq 6.5 \%,<8 \%$, and $\leq 9 \%$ were informed by expert guidelines and clinical trials $[5,19-21]$. The results from the multivariable analyses which examined annual diabetes-related total costs are provided in Fig. 3, while component costs are given in Table 2. As Fig. 3 and Table 2 show, at all thresholds, those who achieved the HbA1c target had significantly lower mean diabetes-related total and component costs. For example, annual diabetes-related total costs were $12.4 \%, 14.9 \%, 18.9 \%$, and $16.3 \%$ lower for patients with HbA1c $<6 \%$, $\leq 6.5 \%,<8 \%$, and $\leq 9 \%$, respectively, compared to patients above such targets. Furthermore, costs increased as the HbA1c threshold increased.

\section{DISCUSSION}

This study compared the annual diabetes-related costs of patients with index HbA1c $<7 \%$ to costs for patients with index $\mathrm{HbA} 1 \mathrm{c} \geq 7 \%$. 
Table 1 Descriptive statistics

\begin{tabular}{|c|c|c|c|c|}
\hline & $\begin{array}{l}\text { All patients } \\
(N=34,538)\end{array}$ & $\begin{array}{l}\text { Index HbA1c }<7 \% \\
(N=17,269)\end{array}$ & $\begin{array}{l}\text { Index HbAlc } \geq 7 \% \\
(N=17,269)\end{array}$ & $P$ value \\
\hline \multicolumn{5}{|c|}{ Patient demographics (measured at baseline) } \\
\hline Age $($ mean $\pm S D)$ & $72.7 \pm 10.3$ & $73.5 \pm 10.4$ & $71.9 \pm 10.2$ & $<0.0001$ \\
\hline Sex & & & & 0.0105 \\
\hline Female & $18,348(53.1)$ & $9314(53.9)$ & $9034(52.3)$ & \\
\hline Male & $16,188(46.9)$ & $7954(46.1)$ & $8234(47.7)$ & \\
\hline Unknown & $2(0.0)$ & $1(0.0)$ & $1(0.0)$ & \\
\hline Race/ethnicity & & & & 0.1134 \\
\hline Asian & $828(2.4)$ & $429(2.5)$ & $399(2.3)$ & \\
\hline Black & $4990(14.4)$ & $2420(14.0)$ & $2570(14.9)$ & \\
\hline Hispanic & $5559(16.1)$ & $2812(16.3)$ & $2747(15.9)$ & \\
\hline White & $18,564(53.7)$ & $9334(54.1)$ & $9230(53.4)$ & \\
\hline Unknown & $4597(13.3)$ & $2274(13.2)$ & $2323(13.5)$ & \\
\hline Region & & & & $<0.0001$ \\
\hline Midwest & $4938(14.3)$ & $2446(14.2)$ & $2492(14.4)$ & \\
\hline Northeast & $3959(11.5)$ & $1726(10.0)$ & $2233(12.9)$ & \\
\hline South & $17,367(50.3)$ & $8688(50.3)$ & $8679(50.3)$ & \\
\hline West & $8252(23.9)$ & $4395(25.5)$ & $3857(22.3)$ & \\
\hline Other/Unknown & $22(0.1)$ & $14(0.1)$ & $8(0.0)$ & \\
\hline Insurance product type & & & & $<0.0001$ \\
\hline Health maintenance organization & $11,695(33.9)$ & $6264(36.3)$ & $5431(31.4)$ & \\
\hline Point of service & $2086(6.0)$ & $989(5.7)$ & $1097(6.4)$ & \\
\hline Preferred provider organization & $2806(8.1)$ & $1431(8.3)$ & $1375(8.0)$ & \\
\hline Other & $17,951(52.0)$ & $8585(49.7)$ & $9366(54.2)$ & \\
\hline \multicolumn{5}{|c|}{ Pre-period general health and comorbidities } \\
\hline Adjusted CCI (mean \pm SD) & $1.0 \pm 2.2$ & $1.1 \pm 2.2$ & $0.9 \pm 2.1$ & $<0.0001$ \\
\hline DCSI score $($ mean $\pm S D)$ & $1.3 \pm 1.1$ & $1.2 \pm 1.1$ & $1.4 \pm 1.1$ & $<0.0001$ \\
\hline Anxiety & $911(2.6)$ & $516(3.0)$ & $395(2.3)$ & $<0.0001$ \\
\hline Depression & $1690(4.9)$ & $905(5.2)$ & $785(4.5)$ & 0.0028 \\
\hline \multicolumn{5}{|l|}{ Pre-period resource use } \\
\hline Cardiologist & $24,497(70.9)$ & $12,296(71.2)$ & $12,201(70.7)$ & 0.2603 \\
\hline Endocrinologist & $5598(16.2)$ & $2045(11.8)$ & $3553(20.6)$ & $<0.0001$ \\
\hline Nephrologist & $9152(26.5)$ & $4707(27.3)$ & $4445(25.7)$ & 0.0014 \\
\hline
\end{tabular}


Table 1 continued

\begin{tabular}{|c|c|c|c|c|}
\hline & $\begin{array}{l}\text { All patients } \\
(N=34,538)\end{array}$ & $\begin{array}{l}\text { Index HbA1c }<7 \% \\
(N=17,269)\end{array}$ & $\begin{array}{l}\text { Index HbA1c } \geq 7 \% \\
(N=17,269)\end{array}$ & $P$ value \\
\hline Ophthalmologist & $14,710(42.6)$ & $7324(42.4)$ & $7386(42.8)$ & 0.4999 \\
\hline $\begin{array}{l}\text { No. of family practice/internist visits } \\
(\text { mean } \pm \mathrm{SD})\end{array}$ & $17.4 \pm 16.9$ & $18.0 \pm 17.6$ & $16.7 \pm 16.2$ & $<0.0001$ \\
\hline \multicolumn{5}{|l|}{ Pre-period medication use } \\
\hline $\begin{array}{l}\text { No. of classes of insulin prescribed } \\
(\text { mean } \pm S D)\end{array}$ & $0.6 \pm 0.8$ & $0.3 \pm 0.6$ & $0.8 \pm 0.9$ & $<0.0001$ \\
\hline $\begin{array}{l}\text { No. of classes of non-insulin } \\
\text { prescribed }(\text { mean } \pm S D)\end{array}$ & $1.1 \pm 1.0$ & $1.0 \pm 0.9$ & $1.2 \pm 1.1$ & $<0.0001$ \\
\hline $\begin{array}{l}\text { No. of non-GLAs prescribed } \\
(\text { mean } \pm \mathrm{SD})\end{array}$ & $14.7 \pm 8.5$ & $14.6 \pm 8.5$ & $14.9 \pm 8.6$ & 0.0012 \\
\hline \multicolumn{5}{|l|}{ Index $\mathrm{HbAlc}$} \\
\hline HbAlc (mean \pm SD) & $7.4 \pm 1.8$ & $6.1 \pm 0.5$ & $8.7 \pm 1.6$ & $<0.0001$ \\
\hline
\end{tabular}

Data are presented as $N(\%)$ unless specified otherwise

CCI Charlson Comorbidity Index, DCSI Diabetes Complications Severity Index, GLA glucose-lowering agent, HbAIc hemoglobin A1c, $S D$ standard deviation

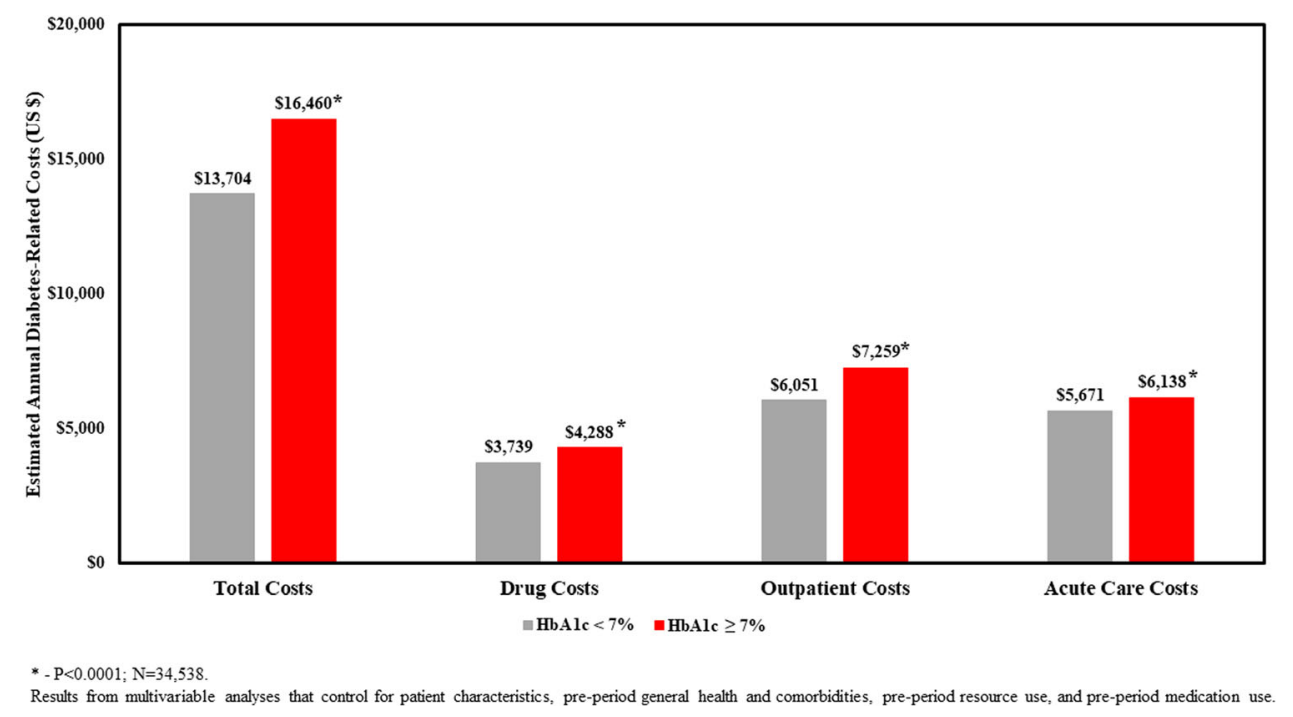

Fig. 2 Association between index HbAlc and annual diabetes-related costs 


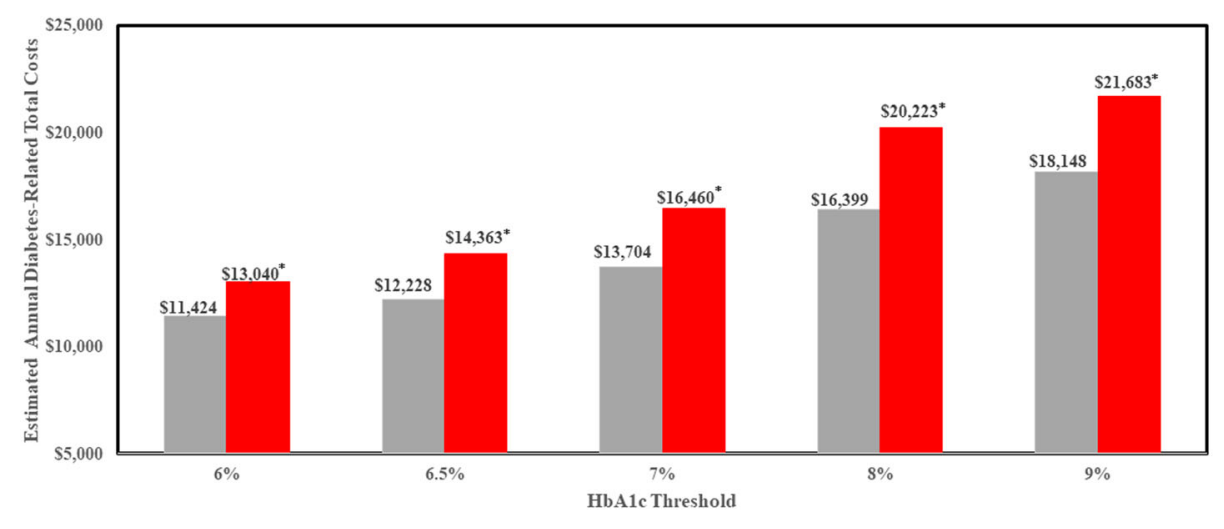

a HbAlc Below Threshold $\quad$ HbAlc Above Threshold

* Difference in cost for patients below threshold signific antly different compared to costs for patients above threshold $(\mathrm{P}<0.0001)$.

Thresholds are $<6 \% \mathrm{v} \geq 6 \%(\mathrm{~N}=14,646) ; \leq 6.5 \% \mathrm{v}>6.5 \%(\mathrm{~N}=30,350) ;<7 \% \mathrm{v} \geq 7 \%(\mathrm{~N}-34,538) ;<8 \% \mathrm{v} \geq 8 \%(\mathrm{~N}=19,650) ;$ and $\leq 9 \% \mathrm{v}>9 \%(\mathrm{~N}=10,532)$.

Thresholds are $<6 \% \mathrm{v} \geq 6 \%(\mathrm{~N}=14,646) ; \leq 6.5 \% \mathrm{v}>6.5 \%(\mathrm{~N}=30,350) ;<7 \% \mathrm{v} \geq 7 \%(\mathrm{~N}-34,538) ;<8 \% \mathrm{v} \geq 8 \%(\mathrm{~N}=19,650) ;$ and $\leq 9 \% \mathrm{v}>9 \%(\mathrm{~N}=10,532)$.
Results from multivariable analyses that control for patient characteristics, pre-period general health and comorbidities, pre-period resource use, and pre-period medication use.

Results from multivariable analyses that control for patient characteristics, pre-period general health and comorbidities, pre-period resource use, and pre-period medication
Results indicate that, at all thresholds, lower HbAlc is associated with statistically significantly lower annual diabetes-related total costs. In addition, as Hbalc threshold

increases, annual diabetes-related total costs increase.

Fig. 3 Estimated annual diabetes-related total costs for alternative HbAlc thresholds

The results indicate that glycemic control is associated with significantly lower diabetes-related total, outpatient, acute care, and drug costs.

The present findings are consistent with research examining total medical costs. For example, research from Saudi Arabia found that lower $\mathrm{HbA1c}$ was associated with lower total direct medical costs [22]. In addition, a study from Brazil found lower total costs and medication costs for individuals with HbA1c $\leq 7 \%$ (vs $>7 \%$ ) and for individuals with HbA1c $\leq 8 \%$ (vs $>8 \%$ ) [23]. A previous retrospective study found that $\mathrm{HbA} 1 \mathrm{c}<7 \%$, compared to $\mathrm{HbA} 1 \mathrm{c}$ $\geq 7 \%$, was associated with lower diabetes-related total, acute care, outpatient, and drug costs [24]. The finding of significantly higher diabetes-related drug costs for patients with higher HbA1c is consistent with the hypothesis that patients with higher HbA1c are in need or more intensive or additional therapies.

Results of the sensitivity analyses revealed that as HbA1c thresholds increase, diabetes-related costs increase. This finding is consistent with previous research which has shown that worse glycemic control is associated with higher diabetes-related costs. For example, a retrospective study utilizing data from Italy found that lower levels of HbA1c were associated with lower diabetes-related costs [25]. Research from the USA in 2007 found that for individuals with T2D a 1\% increase in HbA1c was associated with a $4.4 \%$ increase in diabetes-related medical costs [26]. More recent research found that for patients with $\mathrm{T} 2 \mathrm{D}$, a $1 \%$ reduction in HbA1c was associated with a $13 \%$ reduction in diabetes-related total healthcare costs [24].

The findings of the current study must be interpreted within the context of the limitations. One limitation is that insurance claims describe only commercially insured patients, which may limit the generalizability of the findings. Secondly, using diagnostic codes is less rigorous than employing formal assessments to identify patients with T2D. Thirdly, the use of claims data precluded studying, or controlling for, body mass index, duration of diabetes, or other potentially influential factors which were not available in the data. In addition, these claims-based analyses focused on statistical significance rather than clinical significance and associations rather than causation.

\section{CONCLUSIONS}

This study used data from insurance claims to assess associations between glycemic control and diabetes-related medical costs among a 
Table 2 Diabetes-related component costs at alternative HbAlc thresholds

Index HbAlc $<6 \%(N=7323)$

Index $\mathrm{HbA1c} \geq 6 \%(N=7323)$

HbAlc threshold of 6\%

Diabetes-related component costs

$\begin{array}{lll}\text { Drug* }^{*} & \$ 2957 \pm \$ 4403 & \$ 3373 \pm \$ 4600 \\ \text { Outpatient* }^{*} & \$ 5117 \pm \$ 5736 & \$ 5811 \pm \$ 6273 \\ \text { Acute care* }^{*} & \$ 4871 \pm \$ 3990 & \$ 5085 \pm \$ 4069\end{array}$

Index HbAlc $\leq 6.5 \%(N=15,175)$

Index HbAlc $>6.5 \%(N=15,175)$

HbAlc threshold of $6.5 \%$

Diabetes-related component costs
Drug*
$\$ 3351 \pm \$ 4685$
$\$ 3812 \pm \$ 4910$
Outpatient*
$\$ 5552 \pm \$ 6173$
$\$ 6514 \pm \$ 6875$
Acute care*
$\$ 5056 \pm \$ 3867$
$\$ 5354 \pm \$ 3899$

Index HbAlc $<8 \%(N=9825)$

Index HbA1c $\geq 8 \%(N=9825)$

HbAlc threshold of $8 \%$

Diabetes-related component costs

$\begin{array}{lll}\text { Drug* }^{*} & \$ 4398 \pm \$ 4333 & \$ 5018 \pm \$ 4524 \\ \text { Outpatient* }^{*} & \$ 6805 \pm \$ 7435 & \$ 8608 \pm \$ 8423 \\ \text { Acute care* } & \$ 6889 \pm \$ 4991 & \$ 7549 \pm \$ 4961\end{array}$

Index HbAlc $\leq 9 \%(N=5266)$

Index HbAlc > 9\% $(N=5266)$

HbAlc threshold of $9 \%$

Diabetes-related component costs
Drug*
$\$ 4838 \pm \$ 4690$
$\$ 5684 \pm \$ 5022$
Outpatient*
$\$ 6711 \pm \$ 6187$
$\$ 7952 \pm \$ 6847$
Acute care*
$\$ 8005 \pm \$ 5273$
$\$ 8355 \pm \$ 5425$

Results from multivariable analyses which control for patient characteristics, pre-period general health and comorbidities, pre-period resource use, and pre-period medication use

$H b A 1$ hemoglobin A1c, SD standard deviation

*Indicates statistically significant differences between the two groups $(P<0.0001)$

population of US patients with T2D. The findings revealed that individuals whose index HbA1c was below the ADA target for glycemic control $(\mathrm{HbA} 1 \mathrm{c}<7 \%)$ had substantially lower 1 -year diabetes-related costs relative to patients with less glycemic control (HbA1c $\geq 7 \%$ ).
Glycemic control was associated with significant reductions in annual diabetes-related component and total costs. Results suggest economic benefits associated with having HbA1c at or below target. 


\section{ACKNOWLEDGEMENTS}

Funding. All funding for this study, including payment of the Rapid Service Fee, was provided by Eli Lilly and Company.

Authorship. All named authors meet the International Committee of Medical Journal Editors (ICMJE) criteria for authorship for this article, take responsibility for the integrity of the work as a whole, and have given their approval for this version to be published.

Author Contributions. KSB conceptualized the study and was responsible for funding acquisition. MJL conducted the analyses and drafted the manuscript. All authors were responsible for study design and review and editing of manuscript. All authors read and approved the final manuscript.

Disclosures. The authors Boye and Thieu are employees and shareholders of Eli Lilly and Company and conducted this research as part of their employment. Lage was compensated by Eli Lilly and Company for her work on this research. Eli Lilly funded the journal's Rapid Service fee.

Compliance with Ethics Guidelines. As a retrospective study which used de-identified data, the study did not seek institution review board approval. Permission to access data from Optum were obtained via purchase of a data license. The linked data are fully de-identified and Health Insurance Portability and Accountability Act (HIPAA) compliant.

Data Availability. Optum ${ }^{\circledR}$ data used for this study are available via licensing agreement.

Open Access. This article is licensed under a Creative Commons Attribution-NonCommercial 4.0 International License, which permits any non-commercial use, sharing, adaptation, distribution and reproduction in any medium or format, as long as you give appropriate credit to the original author(s) and the source, provide a link to the Creative Commons licence, and indicate if changes were made. The images or other third party material in this article are included in the article's Creative Commons licence, unless indicated otherwise in a credit line to the material. If material is not included in the article's Creative Commons licence and your intended use is not permitted by statutory regulation or exceeds the permitted use, you will need to obtain permission directly from the copyright holder. To view a copy of this licence, visit http://creativecommons.org/licenses/by$\mathrm{nc} / 4.0 /$.

\section{REFERENCES}

1. Centers for Disease Control and Prevention. National Diabetes Statistics Report, 2020. https:// www.cdc.gov/diabetes/library/features/diabetesstat-report.html. Accessed 30 Sep 2021.

2. Lin J, Thompson TJ, Cheng YJ, et al. Projection of the future diabetes burden in the United States through 2060. Popul Health Metr. 2018. https:// doi.org/10.1186/s12963-018-0166-4.

3. American Diabetes Association. Economic costs of diabetes in the U.S. in 2017. Diabetes Care. 2018;41(5):917-28.

4. Centers for Disease Control and Prevention. Diabetes: diabetes fast facts, 2020. https://www.cdc. gov/diabetes/basics/quick-facts.html. Accessed 30 Sep 2021.

5. American Diabetes Association. 6. Glycemic targets: standards of medical care in diabetes-2021. Diabetes Care. 2021;44(Suppl 1):S73-84.

6. Heller SR, ADVANCE Collaborative Group. A summary of the ADVANCE trial. Diabetes Care. 2009;32(2):S357-61.

7. Ohkubo Y, Kishikawa H, Araki E, et al. Intensive insulin therapy prevents the progression of diabetic microvascular complications in Japanese patients with non-insulin-dependent diabetes mellitus: a randomized prospective 6-year study. Diabetes Res Clin Pract. 1995;28(2):103-17.

8. UK Prospective Diabetes Study (UKPDS) Group. Intensive blood-glucose control with sulphonylureas or insulin compared with conventional treatment and risk of complications in patients with type 2 diabetes (UKPDS 33). Lancet. 1998;352(9131):837-53. 
9. Fang M. Trends in diabetes management among US adults: 1999-2016. J Gen Intern Med. 2020;35(5): 1427-34.

10. Austin PC. A comparison of 12 algorithms for matching on the propensity score. Stat Med. 2014;33(6):1057-69.

11. U.S. Bureau of Labor Statistics. Consumer price index for all urban consumers: medical care services in the U.S. city average, series ID CUUR0000SAM2, 2021. https://www.bls.gov/data/. Accessed 30 Sep 2021.

12. Barber J, Thompson S. Multiple regression of cost data: use of generalised linear models. J Health Serv Res Policy. 2004;9(4):197-204.

13. Smith VA, Maciejewski ML, Olsen MK. Modeling semicontinuous longitudinal expenditures: a practical guide. Health Serv Res. 2018;53(Suppl 1): 3125-47.

14. Polgreen LA, Brooks JM. Estimating incremental costs with skew: a cautionary note. Appl Health Econ Health Policy. 2012;10(5):319-29.

15. Glasheen WP, Renda A, Dong Y. Diabetes Complications Severity Index (DCSI)-update and ICD-10 translation. J Diabetes Complicat. 2017;31(6): 1007-13.

16. Glasheen WP, Cordier T, Gumbina R, Haugh G, David J, Renda A. Charlson Comorbidity Index: ICD-9 update and ICD-10 translation. Am Health Drug Benefits. 2019;12(4):188-97.

17. Stuart EA. Matching methods for causal inference: a review and a look forward. Stat Sci. 2010;25(1): $1-21$.

18. Austin PC. Balance diagnostics for comparing the distribution of baseline covariates between treatment groups in propensity-score matched samples. Stat Med. 2009;28(25):3083-107.
19. Action to Control Cardiovascular Risk in Diabetes (ACCORD) Study Group. Effects of Intensive glucose lowering in type 2 diabetes. $\mathrm{N}$ Engl J Med. 2008;358(24):2545-59.

20. National Committee for Quality Assurance (NCQA). HEDIS measures and technical resources: comprehensive diabetes care (CDC), 2018. https:// www.ncqa.org/hedis/measures/comprehensivediabetes-care/. Accessed 30 Sep 2021.

21. Garber AJ, Handelsman Y, Grunberger G, et al. Consensus statement by the American Association of Clinical Endocrinologists and American College of Endocrinology on the comprehensive type 2 diabetes management algorithm - 2020 executive summary. Endocr Pract. 2020;26(1):107-39.

22. Almutairi N, Alkharfy KM. Direct medical cost and glycemic control in type 2 diabetic Saudi patients. Appl Health Econ Health Policy. 2013;11(6):671-5.

23. Henriques RS, Steimbach LM, Baptista DR, et al. Direct costs of type 2 diabetes: a Brazilian cost-ofillness study. Int J Technol Assess Health Care. 2018;34(2):180-8.

24. Lage MJ, Boye KS. The relationship between HbA1c reduction and healthcare costs among patients with type 2 diabetes: evidence from a U.S. claims database. Curr Med Res Opin. 2020;36(9):1441-7.

25. Degli Esposti L, Saragoni S, Buda S, et al. Glycemic control and diabetes-related health care costs in type 2 diabetes; retrospective analysis based on clinical and administrative databases. Clinicoecon Outcomes Res. 2013;5:193-201.

26. Aagren M, Luo W. Association between glycemic control and short-term healthcare costs among commercially insured diabetes patients in the United States. J Med Econ. 2011;14(1):108-14. 